\title{
Communication
}

\section{Sustainability of the Renewable Energy Extraction Close to the Mediterranean Islands}

\author{
Vincenzo Franzitta * and Domenico Curto \\ Department of Energy, Information and Mathematical models, University of Palermo (UNIPA), 90128 Palermo, \\ Italy; domenico.curto@unipa.it \\ * Correspondence: franzitta@dream.unipa.it; Tel.: +39-091-2386-1941
}

Academic Editor: Frede Blaabjerg

Received: 10 December 2016; Accepted: 21 February 2017; Published: 27 February 2017

\begin{abstract}
The aim of this work is to explore the possibility of transitioning a fuel powered island to a renewable powered one. This transition is analyzed for the real MV/LV distribution system of the island of Pantelleria, in the Mediterranean Sea. Particularly, this work is focused on a renewable source nowadays totally unused: wave energy. Thanks to the innovative generator prototype designed by Department of Energy of University of Palermo (Italy), wave energy is able to represent a primary source for the production of electric energy in the Mediterranean islands. The procedures applied in the present article, as well as the main equations used, are the result of previous applications made in different technical fields that show a good replicability.
\end{abstract}

Keywords: wave energy conversion; Mediterranean Sea; point absorber; Pantelleria Island

\section{Introduction}

During the past few years, European Union countries have focused their attention on the the production of electrical energy from renewable sources. This particular interest is due to many factors. The first one is the reduction of greenhouse gases (GHG) emissions generated by the energy sector. In fact, a fully-based electrical energy production on fossil fuel power plants represents an important item of the global emissions of GHG, especially $\mathrm{CO}_{2}$. Thanks to accurate energy policies and a continuous technological innovation of conversion devices [1], nowadays Renewable Energy (RE) production has a very important role in every energetic sector, such as in the electrical power production (thanks to the installation of photovoltaic panels or wind turbines), indoor heating [2] (thanks to solar thermal panels) and bio-fuel production (for example bio-diesel, bio-methane, etc.). Additionally, a significant use of RE is important to satisfy the objectives fixed in the Kyoto Protocol (1997) and the following 20-20-20 Package on Climate Change [3]. The first one obliges signatories to reduce polluting emissions (firstly of carbon dioxide, but also for other five greenhouse gases: methane, nitrogen oxide, hydrofluorocarbons, perfluorocarbons, sulfur hexafluoride) by at least $5 \%$ compared to the emissions recorded in 1985. Instead, the 20-20-20 Package outlines the objectives that each European Country must reach before 2020: a 20\% reduction of greenhouse emissions compared to the 1990 levels, a 20\% renewable energy item in the final energy consumption and an increase of the energy efficiency of the $20 \%$, which can be obtained also through the use of sustainable buildings [4]. The second role of RE is due to the possibility of reduction of energetic dependence of a country, especially if this country has no endogenous fossil fuels [5]. The third one is linked to the creation of a supply chain that still does not exist today [6].

In these years, Italy improved its exploitation of renewable energy sources: for example, in the only 2013 the renewable energy production was about 20.7 Mtep, while the electrical energy production was about 112 TWh (9.6 Mtep), with an installed power of 50 GW [7]. However, in small islands (such as Pantelleria) the use of RE is strongly underdeveloped. Therefore, a remarkable role of RE in the 
Italian islands is now really important, in order to satisfy in loco their electrical demands, reducing their dependence on the mainland. Obviously, the use of wave energy can be a significant contributor to reaching this important goal. A very interesting example of a literature review of the problem on Pantelleria Island is exposed in [8], in which a $60 \mathrm{~kW}$ converter prototype was tested. This device, with a total conversion efficiency of $45 \%$, shows that new conversion technologies can be applied and represents a remarkable step in the development of a renewable energy-based island. Moreover, different authors have focused their attention on the self-sufficiency of small islands, thanks to the use of renewable energies, such as solar, wind and hydroelectric. One of the most important example is represented by El Hierro [9], the smallest island of the Canary Archipelago (Spain), in which a significant part of the annual electrical request will be produced by the local hydroelectric power plant, with the remainder provided by wind turbines and photovoltaic panels. Instead, this text is fundamentally focused on wave energy, which represents a particular type of RE nowadays totally unused, despite its interesting potential. The characterization of wave resource is here exposed, in order to show the relationship between wave high, period and its theoretical extractable power. The aim of this article is to analyze the traditional electrical energy production in Pantelleria and the sea wave energy potential along its coasts, in order to understand the applicability and the energy capability of a new conversion device nowadays in the design phase by Department of Energy of University of Palermo, called DEIM Point Absorber.

\section{Pantelleria's Environmental Policies and Landscape}

Pantelleria, like several other Italian islands (for example Favignana, Lampedusa, Linosa, Leni, Lipari, Salina, Ustica) has subscribed the Pact of Islands, in which insular mayors undertook the UE objectives in order to reduce $\mathrm{CO}_{2}$ emissions independently [10]. The subsequent development of the "Plan of Action for Sustainable Energy Island" ("Piano di Azione di Energia Sostenibile dell'isola" in Italian) has allowed the planning of the development of RE. Moreover, in small islands there is an easier control of the environmental results, so, Pantelleria can represent a test site in which new methodologies and new technologies are exposed in order to set up an innovative sustainability model. New energy conversion devices will be able to preserve the island's soil, its fragile ecosystems and biodiversity. Figure 1 shows the location of Pantelleria in the Mediterranean Sea.
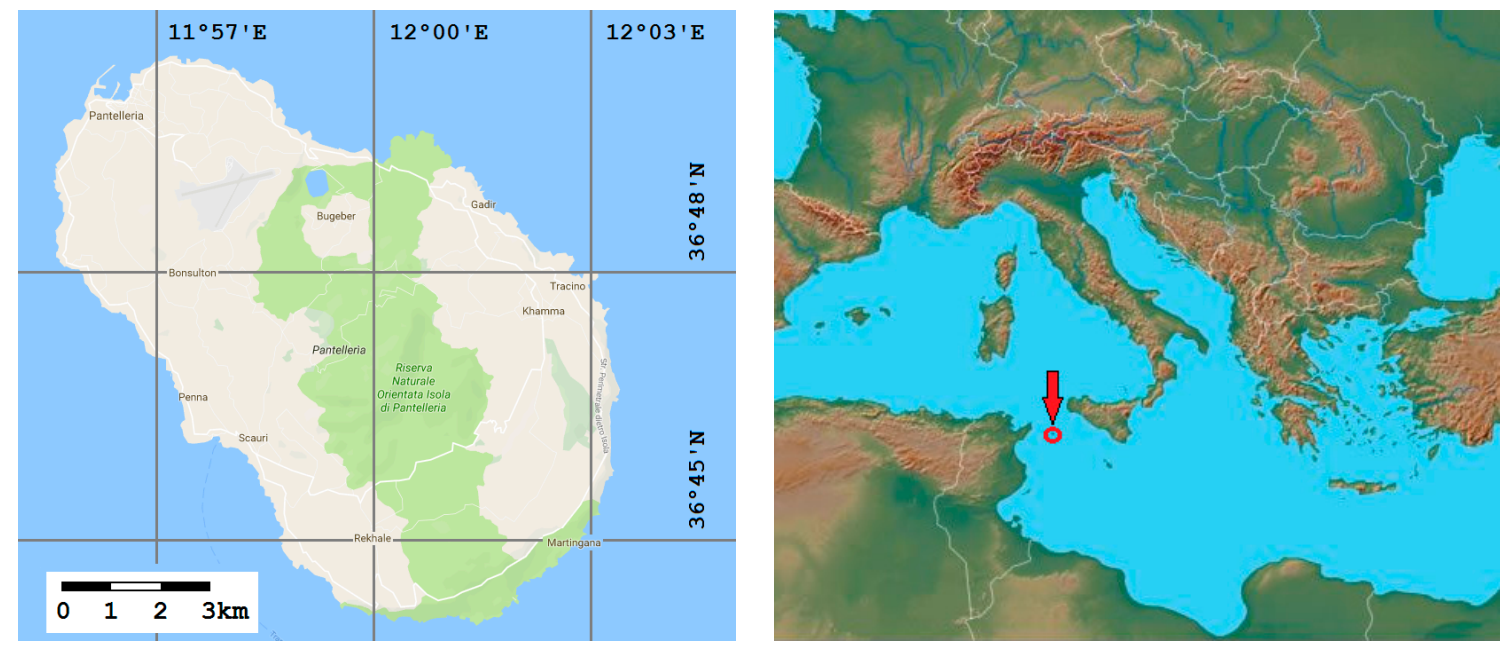

Figure 1. The island of Pantelleria with its location in the Mediterranean Sea.

Electrical energy production on small islands represents an unsustainable model from the economic and environmental point of view. In fact, the cost of electrical energy is higher than on the mainland, although the final price payed by the citizens is the same thanks to the presence of strong government incentives. For example, only in 2011 the Italian government payed more 
than 5,150,000 $€$ to S.MED.E. S.p.A. (Pantelleria's thermoelectric plant company) in order to cover its economic losses [11]. These higher costs are due to many factors, including the cost of fossil fuel transport from the mainland, low performance of the thermoelectric power plant, high daily and seasonal variations of the electrical energy demand and a total monopoly in the energetic sector. From the environmental point of view, the $\mathrm{CO}_{2}$ emission factor of Pantelleria's power plant is very high: about $0.8 \mathrm{t} / \mathrm{MWh}$ during the period 2009-2013 [12]. This value is more than double the average Italian one $(0.38 \mathrm{t} / \mathrm{MWh})[7]$ and it is basically due to the use of diesel to feed the thermoelectric power plant. Therefore, the use of diesel as fuel implies the emission of large amounts of $\mathrm{CO}_{2}, \mathrm{NO}_{x}$ and $\mathrm{SO}_{x}$ during the fuel combustion and also its transportation, with a significant environmental impact $[13,14]$.

The island of Pantelleria is located in the center of the Sicilian Channel, $110 \mathrm{~km}$ south-west from Sicily (Italy) and $70 \mathrm{~km}$ east-north-east from Tunisia (Africa). Pantelleria has an extension of about $80 \mathrm{~km}^{2}$ and a perimeter of $51.5 \mathrm{~km}$, so it represents the biggest Sicilian island. The population is about 7700 inhabitants, while the population density is about $91.27 \mathrm{inhab} . / \mathrm{km}^{2}$ [15]. However, during summer season, the number of inhabitants increases significantly, thanks to the arrival of tourists. The economy of the island is fundamentally based on tourism and the agricultural sector, especially the cultivation of grapes: Zibibbo, Moscato di Pantelleria, Passito di Pantelleria and Moscato Passito di Pantelleria are the most famous wines exported. On the other side, fishing is poorly practiced. In Pantelleria there are several protected areas. In fact, the island is within the "Natura 2000" network, created by European Union. It is made up of Special Areas of Conservation SACs ("Zona Speciale di Conservazione", ZSC in Italian) and Special Protection Areas SPAs ("Zona di Protezione Speciale", ZPS in Italian), designated under the Habitats Directive and Birds Directive, respectively. This network includes both terrestrial and marine sites. Finally, the island is characterized by some typical buildings, such as Giardini Panteschi and Dammusi. The former are typical cylindrical constructions created to protect citrus trees from the wind, while the latter are buildings constructed to collect rainwater. They are both constructed from lava stone, because of the volcanic origin of the island.

\section{Electrical Energy Production}

At the present time, electrical energy production in Pantelleria is fully based on a conventional thermal power plant. It is composed of eight diesel generators, for a total installed power of about $20 \mathrm{MW}$, whose owner is S.MED.E. S.p.A. As in several Italian small islands, this thermal power plant is largely oversized compared to the local winter demand: this is mainly due to the important increase of electrical energy demand in summer (see Figure 2).

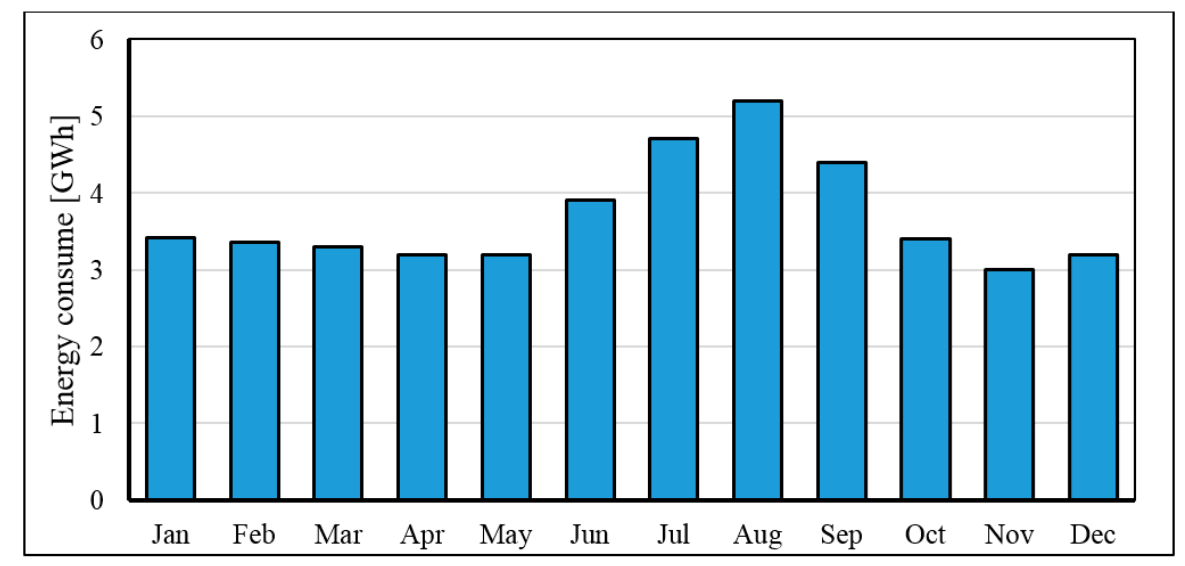

Figure 2. Monthly electrical energy consumption in 2008 [16].

In fact, the load factor is very low, 0.18 , because of the alternate use of the different groups [16]. The electrical energy production increased from the $20 \mathrm{GWh} /$ year during the ' 90 s to $44.1 \mathrm{GWh} /$ year in 2013, with an overall increase of 130\% [7]. Moreover, seasonal variations are very high: for example, 
in 2008 the monthly electrical energy request had a minimum of 3 GWh during November and a maximum of $5 \mathrm{GWh}$ during August. This variation is fundamentally due to the arrival of significant numbers of tourists. Electrical energy represents the first energetic vector of the island and it is used also to produce hot water and heating. These factors increase the consumption of fossil fuel, as exposed in Figure 3. It shows the consumptions of fossil fuel (LPG, Petrol and Diesel) in Ton of Oil Equivalent per person (TOE/person), comparing Pantelleria Island, the Province of Trapani and Sicily. While Liquid Petroleum Gas (LPG) per capita consumption is near to the Sicilian value and Petrol per capita consumption is slightly higher, Diesel consumption is really higher, more than four times. In addition, most of the diesel used is employed in the S.MED.E. power plant. Diesel represents an exogenous fossil fuel, because it is imported in Italy from other countries which are usually characterized by political instability. This fuel arrives in Pantelleria by boat about every week, so exceptional events or bad weather can create many problems to the energy sector of the island and to the transport sector too.

Furthermore, the use of RE represents a great opportunity to cut down the energy dependence of the island, reducing diesel import and the GHG emissions [17]. This important objective can be reach thanks to innovative conversion devices such as the one presented in this work.

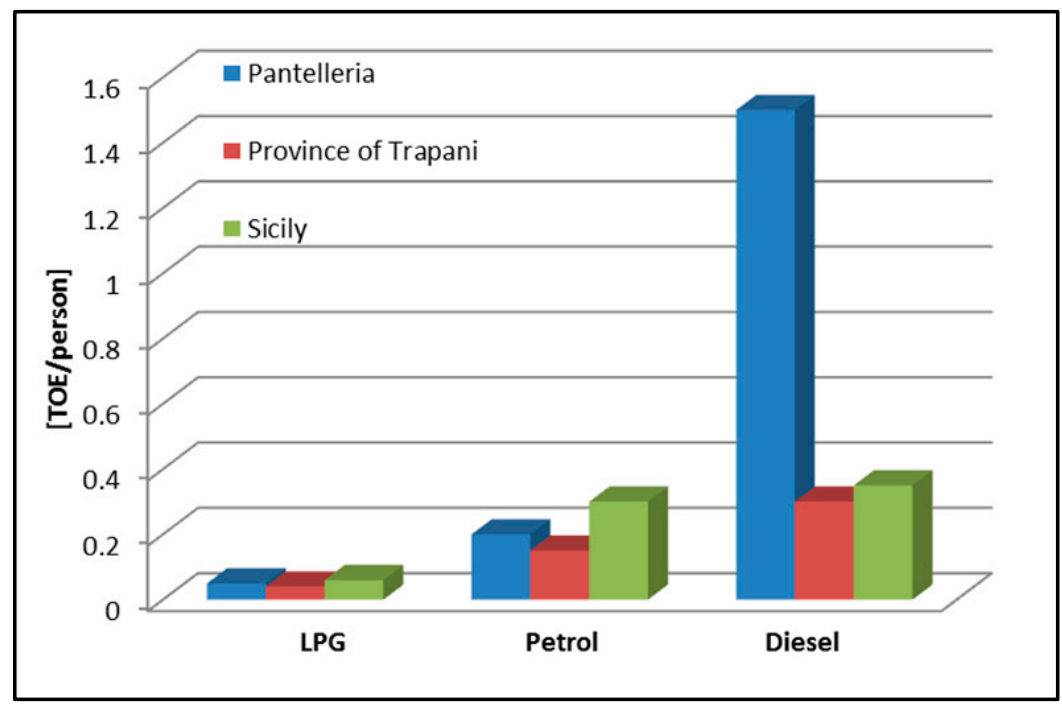

Figure 3. Comparison between the consumption of fossil fuel in Pantelleria, the Province of Trapani and Sicily in 2011 [12].

\section{Seawave Energy Resource}

Thanks to its strategic position in the center of the Mediterranean Sea, between the southern coasts of Sicily and the northern coasts of Africa, the island of Pantelleria is characterized by high values of seawave potential, second only to western coast of Sardinia in the Mediterranean. This is due to the wide fetch in which wind blows and the very deep waters surrounding the island. In fact, the wave energy resource is usually higher off-shore and lower near the coast, because of the seabed friction effects. Furthermore, Pantelleria has a double benefit: a great wave energy resource quite near the coast. This is a very important characteristic, because it makes easier the use of several devices to convert wave energy in electrical output. During these years, different authors have focused their attention on the characterization of wave sources in the Mediterranean Sea, especially along the Italian coast [18]. The first study about wave energy resource near the coasts of Pantelleria was realized by Energia Nucleare ed Energie Alternative (ENEA) through the use of the Simulating WAves Nearshore (SWAN) model [19]. Thanks to this study, the sea wave energy potential was estimated along the entire Mediterranean Sea, identifying the locations of major interest. The following Figure 4 shows the average seasonal distribution of wave power flux in the Mediterranean. Obviously, the wave power flux per unit crest assumes greater values during the winter season and the lower during the summer, 
because of the different weather conditions [20]. From the figure we can see also that Pantelleria Island is located in an area with high energy potential, as already mentioned before.
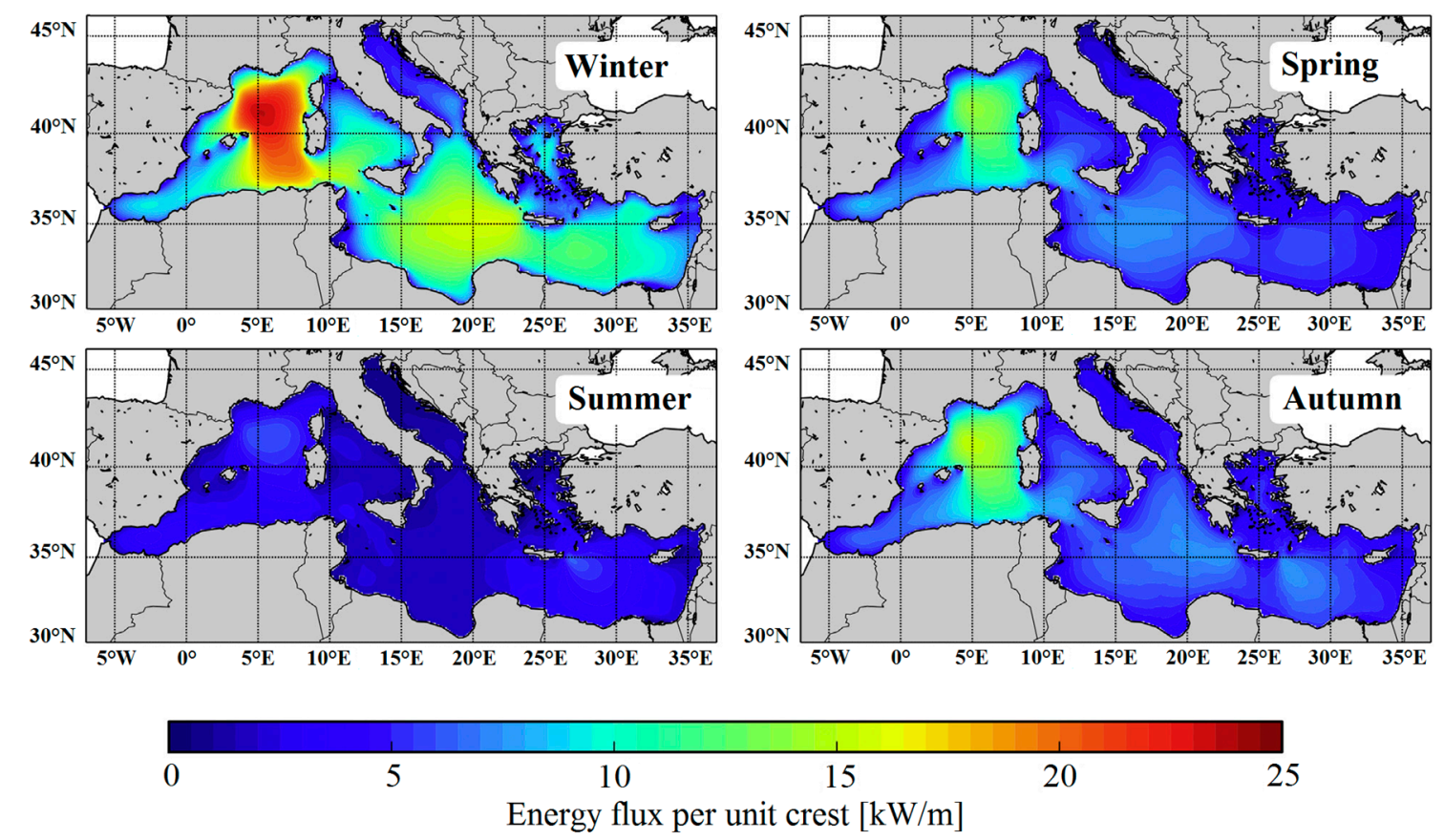

Figure 4. Average seasonal distributions of wave power flux per unit crest in the Mediterranean between 2001 and 2010 [20].

The second study was realized by the Italian Politecnico di Torino, using a Nortek Acoustic Waves and Currents (AWAC) wave-meter, installed at $800 \mathrm{~m}$ off north-west Pantelleria Island and about $34 \mathrm{~m}$ below the sea level. The use of real data which came from an experimental measurement campaign is fundamental to validate software and previous works, despite the high cost of these devices. However, during these years, different authors have focused their attention on the design of low cost weather buoys, in order to reduce their costs, increasing their use in the Mediterranean sea [21]. The Nortek AWAC was able to measure all the main parameters that characterize the wave environment: peak period $T_{p}$ (in seconds), significant wave height $H_{s}$ (in meters), and main direction $D_{p}$. The experimental campaign collected data for one year, from January 2010 to January 2011, in order to know the seasonal variation of wave power near the island's coasts. The average wave power was estimated in $7 \mathrm{~kW} / \mathrm{m}$ (a very high value for the Mediterranean Sea), while the main wave direction is north-west [22]. Moreover, the wave power presented its highest values during the the winter period (twice the average rate) and its lowest values during the summer (about $1 \mathrm{~kW} / \mathrm{m}$ ). Figure 5 shows the resulting scatter table of the extractable energy along Pantelleria's coasts, measured in $\mathrm{kWh} /(\mathrm{m} \cdot$ year). Peak periods are clustered into size intervals equal to $0.5 \mathrm{~s}$, while the significant wave heights were clustered into size intervals of $0.1 \mathrm{~m}$, each of which is representative of a single sea state.

The scatter table shows that the most energetic sea states are those that are characterized by a significant wave height ranging from $1 \mathrm{~m}$ to $3 \mathrm{~m}$ and a peak period ranging from $5 \mathrm{~s}$ to $10 \mathrm{~s}$. The average value of $7 \mathrm{~kW} / \mathrm{m}$ is used in this work to estimate the electrical energy production of the innovative Point Absorber proposed by University of Palermo along the northern coasts of Pantelleria. 


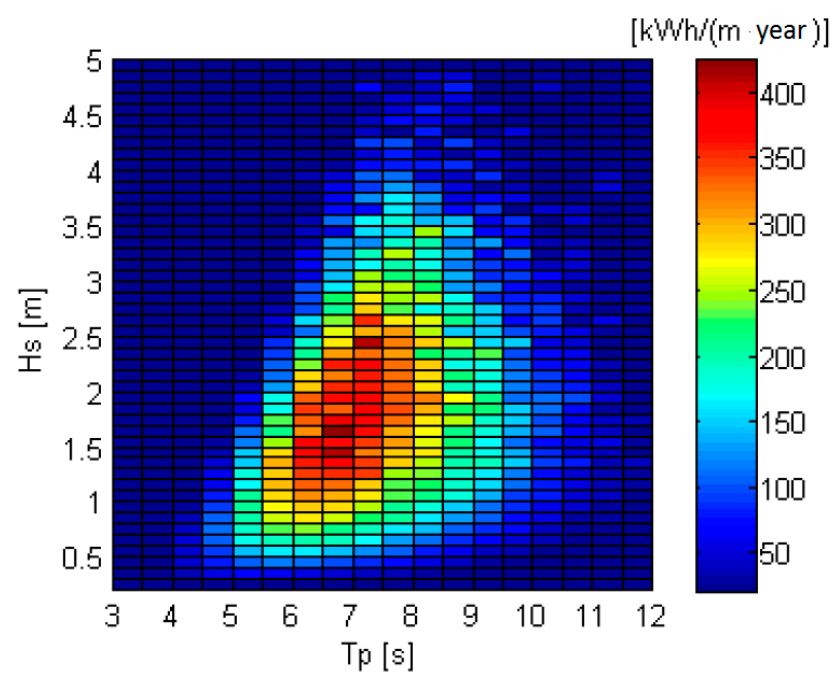

Figure 5. Scattering table of extractable energy along Pantelleria's coasts [22].

\section{Mathematical Modeling}

As shown in the following details, the DEIM point absorber is composed by two coaxial cylindrical buoys. The central buoy is fixed to the seabed, while the external is able to move vertically. Neglecting the fixed buoy, the sea wave energy converter can be modeled as a single body having one degree of freedom along the vertical axis $y$ [23]. The WEC behavior is simulated in the time domain, because of the non-linearity of the power take off (PTO) system. At this step, regular waves are assumed, in order to simplify the equations [24]. This is a limitation for the model, because time domain approaches with irregular wave inputs would fit better in the general context [25]. Nevertheless, the differences between the two approaches are limited, especially for short waves, like in the Mediterranean Sea [26]. Furthermore, at this step our goal is to assess the interactions between sea waves and the energy converter device, evaluating the electrical energy production. In this way, it is possible to proceed with the design and development of the conversion. According to this goal, we believe that the simplified model of regular waves is adequate and acceptable. The vertical motion of the floating buoy is determined by solving the following equation, which considers the hydrodynamic forces $F_{H}(t)$ and the resistance forces $F_{R}(t)$ due to the power take off (PTO) system:

$$
m \ddot{y}(t)=F_{H}(t)+F_{R}(t)
$$

where $m$ is the total mass of the system and $\ddot{y}(t)$ represents its vertical acceleration. The hydrodynamic forces on the heaving buoy is evaluated by:

$$
F_{H}(t)=-m_{a} \ddot{y}(t)-R_{D} \dot{y}(t)-\frac{1}{2} C_{D} \rho S[\dot{y}(t)-\dot{\eta}(t)] *|\dot{y}(t) \dot{\eta}(t)|-\rho g S y(t)+F_{e} \frac{H}{2} \cos (\omega t+\alpha)
$$

where $y(t)$ is the vertical coordinate at time $t$, measured from the initial equilibrium position. The five terms on the right side of the equation represent the different forces acting on the buoy: (1) considers the added inertial force, due to the motion of fluid (having the mass $m_{a}$ ) caused by the buoy; (2) radiation damping force, due to the waves generated by buoy oscillations, where $R_{D}$ is the radiation damping coefficient; (3) viscous damping force accounting for relative turbulent flow, where $\rho$ is sea water density, $S$ is the waterplane area of the body at rest, $C_{D}$ is the viscous damping coefficient, set equal to one [27], and $\dot{\eta}(t)$ is the vertical velocity of the free water surface; (4) hydrostatic restoring force, where $g$ is gravity; and (5) vertical component of the excitation force, due to the incident waves on the assumedly fixed body, where $F_{e}$ is force amplitude, $H$ and $\omega$ are, respectively, wave height and frequency and $\alpha$ is the phase angle between the wave and the wave-induced heaving force. In turn, 
the excitation force can be decomposed into two contributions: the diffraction force considering the wave deformation, generated by the structure and the Froude-Krylov force, due to the undisturbed wave field. If the floating buoy is very small compared with the wavelength, diffraction force can be neglected, so the excitation force is can be assumed equal to only the Froude-Krylov [28]. In the present analysis, the full expression of the excitation force is considered. The resistance force, $F_{R}$, generated by the PTO system, is modeled as:

$$
F_{R}(t)=-F_{M}(t)-F_{K}(t)
$$

where $F_{M}(t)$ is the electromagnetic braking force, caused by the electrical power production inside the linear generator, and $F_{K}(t)$ is the elastic force of the spring system, connected to the translator, which is calculated by:

$$
F_{K}(t)=K \times y(t)
$$

where $K$ is the elastic stiffness constant of the spring. The electromagnetic force can be evaluated applying the Faraday's law and the Maxwell equations to the electro-magnetic structure of sea wave energy converter. A simplified analytical model, presented by Thorburn and Leijon [29], is used to calculate the voltage generated in the stator, $e(t)$ :

$$
e(t)=\frac{2 \pi \cdot B_{t} \cdot w_{t} \cdot d \cdot s \cdot q \cdot c}{w_{p}} \cdot \dot{y}(t) \cdot \sin \left[\frac{2 \pi}{w_{p}} y(t)-\delta\right]
$$

where $B_{t}$ is the magnetic field evaluated in stator tooth, $w_{t}$ is the width of a stator tooth, $d$ is the width of the stator stack, $p$ is the total number of poles, $s$ is the number of slots per pole and phase, $c$ is the number of coils in a slot, $w_{p}$ is the pole width and $\delta$ is the load angle. Considering the energy supply to a purely resistive load and using the equivalent electric circuit, the voltage, $V(t)$, and the current, $I(t)$, measured at the terminals of each phase are, respectively, evaluated by:

$$
\begin{gathered}
V(t)=e(t)-R_{i} I(t)-L \frac{d I(t)}{d t} \\
I(t)=\frac{R_{\text {load }}}{V(t)}
\end{gathered}
$$

where $R_{i}$ is internal resistance of windings, $L$ is circuit inductance and $R_{\text {load }}$ is load resistance. Finally, the output power, $(t)$, and the electromagnetic force, $F_{M}(t)$, are calculated, respectively, by:

$$
\begin{gathered}
P(t)=\sum_{i=1}^{3} V_{i}(t) \cdot I_{i}(t) \\
F_{M}(t)=\frac{\overline{\sum_{i=1}^{3} V_{i}(t) \cdot I_{i}(t)}}{\dot{y}(t) \cdot \varepsilon}
\end{gathered}
$$

where $i$ is the phase index and $\varepsilon$ is the generator efficiency. Several simulations were run, changing the main control parameters of the sea wave energy converter and the state, taking in account the conditions that maximize the electrical energy production. In particular, this condition occurs if the system is in resonance with the dominant wave frequency. A resonant point absorber system has a significantly higher power absorption, thanks its enhanced amplitude and speed in vertical motion [30]. However, for small devices, such as the DEIM point absorber presented here, the resonant frequency of the device tends to values higher than the typical sea state frequency, and so, the resonant condition is practically impossible to achieve. One possible solution consists in increasing the natural period of oscillation of a point absorber, adding a totally submerged mass with neutral buoyancy connected to the floating buoy [31,32]. The additional inertia allows the decreasing of the natural frequency of the device, according with the following equation: 


$$
\omega=\sqrt{\frac{\rho \cdot g \cdot S+K}{m+m_{a}}}
$$

where $m$ is the total mass of the WEC and $m_{a}$ is the total added mass at the frequency of the incident wave. In order to archive the resonance condition of the energy converter to the typical range of sea wave frequency, a spherical body was added as the submerged object, changing the natural frequency of the system. The simulations showed that the maximum power output is achieved when the system resonates with waves having a peak period of $5.5 \mathrm{~s}$, while the optimum natural period of oscillation ranges between 6 and $7 \mathrm{~s}$. For the buoy, the frequency-dependent coefficients of added mass, radiation damping and excitation force were pre-calculated with the commercial software, ANSYS AQWA [33]. The code is based on the boundary element method and on the linear potential wave theory, which is a suitable approximation for the modeling of point absorbers [34].

In order to verify if the design procedure had led to satisfactorily results, several preliminary tests were performed. All tests were performed in a test bench in the laboratory. The tests were focused on the characteristics of the generated emf. The tests measured the no-load and the loaded emf under various speeds of the slider. In Figure 6, the no load emf in the single-phase PM generator is shown for an average speed of $1.6 \mathrm{~m} / \mathrm{s}$. This speed was kept during a single run of the slider on the armature. It corresponds to the simulation of half period [35].

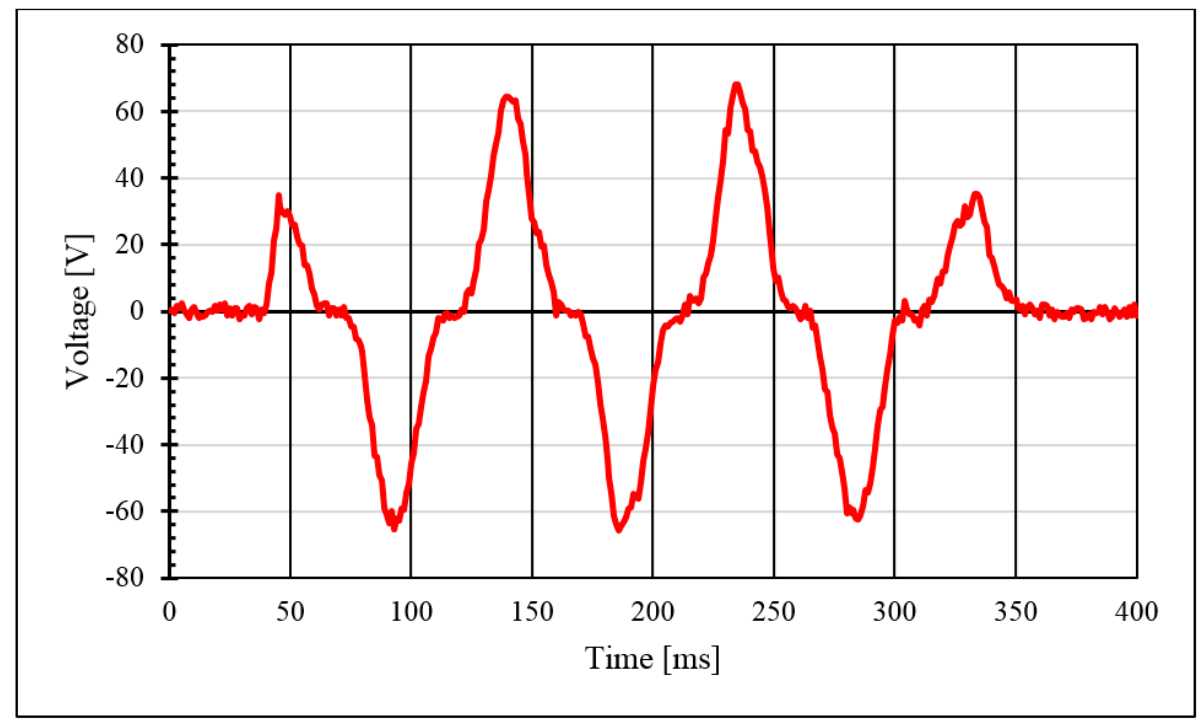

Figure 6. No load emf in the single phase PM generator.

\section{DEIM Point Absorber}

This work describes an innovative device which is able to convert wave energy into electrical energy directly, without the use of other intermediate devices such as pressurized liquids (oils or water), toothed wheels, transmission belts, etc. [36]. During the years, different studies focused their attention to the Point Absorber, which is able to intercept the wave energy from all directions [37]. The optimization of the resulting power performance of this particular type of Wave Energy Converter (WEC) represents the next step in order to improve the economic sustainability of the project [38]. An interesting study about modelling of hydraulic performance of a Point Absorber and its wave energy extraction is exposed in [39], in which an optimal conversion device is evaluated as rated to a $100 \mathrm{~kW}$. A useful solution in order to convert wave energy into electrical output is represented by the use of linear generators, in which the magnetic field is obtained through Permanent Magnets (PM). An interesting study about this Power Take-Off for a wave energy technology is exposed in [40], which is referred to the generator systems of Archimedes Wave Swing (AWS). Instead, the WEC here 
proposed is a different type of Point Absorber, at the present time in the design step by the Department of Energy of the University of Palermo. The authors here proposed this WEC because, as exposed before, it is able to convert wave energy independently from its direction of propagation, which is a very important characteristic increasing the electrical energy output [41].

The DEIM Point Absorber has a nominal power of $160 \mathrm{~kW}$ and it is composed of eight linear generators with a nominal power of $20 \mathrm{~kW}$ each. The nominal power has been chosen in order to optimize the electrical energy output in the particular wave climate of Pantelleria and, at the same time, in order to resist the most energetic sea state. The DEIM WEC is composed by two buoys (as shown in Figure 7), which are able to float independently of each other. An intermittent red light is positioned on top of the buoy, at different heights, making visible the conversion device up to several nautical miles away. The external one (yellow buoy) has a diameter of $10 \mathrm{~m}$, while the internal one (green buoy) has a diameter of $2 \mathrm{~m}$. The first one is able to intercept the wave energy and to transfer it to the second one thanks to the presence of connecting rods (pink rods). A hemispherical weight (red part) is located in the lower part of the inner buoy, guaranteeing its correct vertical positioning and giving it a greater inertia. The green buoy contains all eight linear generators (see Figure 8), which are based on a small scale prototype built in the Department's laboratory.

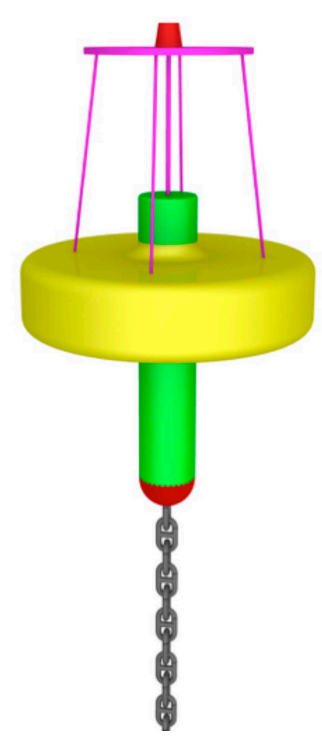

Figure 7. Graphical representation of the DEIM Point Absorber.

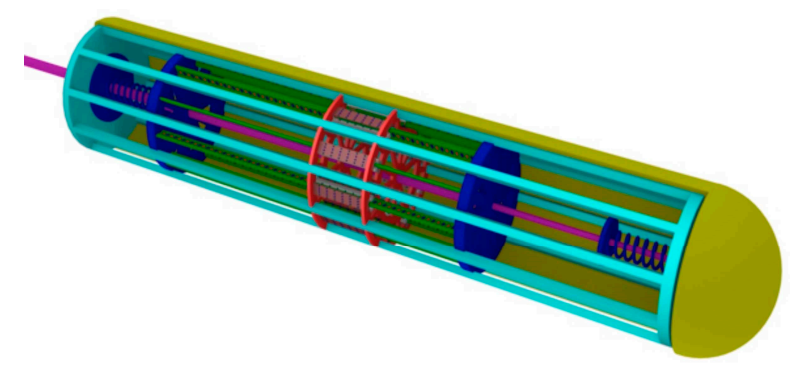

Figure 8. Cross section of the inner buoy of DEIM Point Absorber.

These linear generators have a working stroke of $4 \mathrm{~m}$, in order to use wave energy contained in the most energetic sea state too. There are also two springs in the upper and lower part of the inner case, avoiding any damage of the inner buoy due to bad weather. The Point Absorber here proposed has several innovative aspects, related to the use of a particular type of linear generators that convert directly wave energy to electrical output without the use of brushes or other mechanical devices. Each 
linear generator is composed by a stator part (the external one) a translator part (the internal one). The first one represents the magnetic circuit, composed by two plate packs steel and coils with a three phase connection. The second one is composed by 132 neodymium-iron-boron permanent magnets installed in a bakelite plate with a rotation angle of $13^{\circ}$ in order to minimizing the cogging force between the permanent magnets and the magnetic circuit.

Neodymium-iron-boron magnets can produce an intense magnetic field without an electrical energy demand. The time variation of the magnetic field, due to the vertical alternate motion of the floating body and the consequently relative motion of the translator part compared to the stator part in the inner buoy, produces electromotive forces and, thanks to the resistance of the electrical circuit, the electrical energy. The linear generators are connected to electronic devices, which are used in order to correct the waveform of the electricity here generated. These are fundamental devices, because of the irregular frequencies of the incoming waves. Then, the connection of the systems to the grid is going to be obtained through the use of submarine cables, in order to reduce scraping phenomena and interferences in the seabed.

An electrical efficiency of $50 \%$ is considered here, according to the experimental data obtained on the prototype of the linear generator tested in the laboratory, as shown in Figure 9. The efficiency of the linear generator depends on the load resistance $\mathrm{R}$ and, at the same time, on the weights used in the experimental test $(10,15,20$ and $25 \mathrm{~kg})$ in order to simulate the behavior of the waves on the WEC even in calm sea conditions, giving the movement to the translator part of the conversion device.

Obviously, further studies will be able to improve the overall efficiency, which currently presents high values. Therefore, the particular conversion device here proposed represents an optimal starting point in order to exploit the seawave potential along Pantelleria's coastline, contributing to the important goal of a $100 \%$ renewable island in the Mediterranean Sea. Additionally, DEIM Point Absorbers can be used off-shore, several kilometers away from the coasts, reducing the visual impact on the mainland.

Finally, in order to avoid mutual interference phenomena, these devices will be installed in a line which is normal to the main waves' direction in multiple arrays: in this way, it is possible to create several wave farms with an installed power of different MW in a very restricted area. Moreover, thanks to the high performance of the linear generators constituting the Power Take-Off (PTO) and the high resistance of the construction materials the useful life of the device is about 20 years.

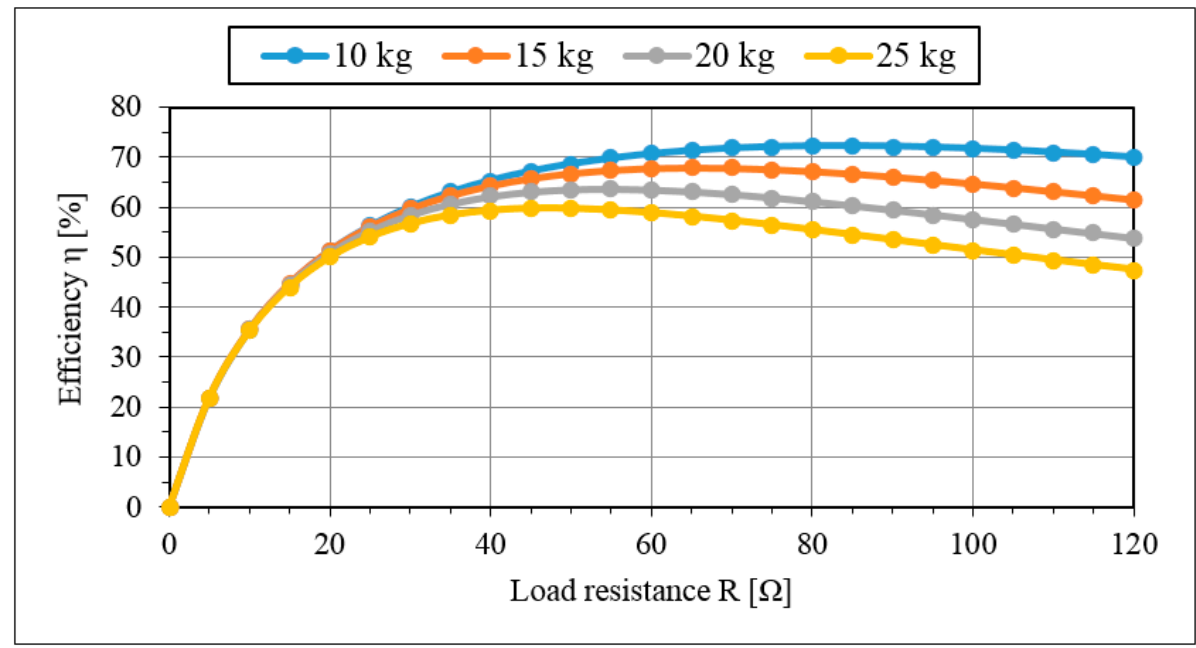

Figure 9. Efficiency of the linear generator in the experimental tests.

\section{Interconnection Solutions}

Currently there is no connection of the DEIM buoy with the electrical grid. In the future will be provided for a submarine cable connection to the island through a conversion substation where 
the energy produced will be supplied to the grid and in a storage system so as to ensure linearity in the power fluctuations. The conversion of an electrical waveform produced from the WEC into an a.c. waveform injectable into the grid is not an easy task. We have examined two approaches: (1) a decentralized approach; and (2) a partially centralized approach [31]. The decentralized approach converts directly from the distorted input to an a.c. output of each machine. The typical structure of the converter is an a.c.-a.c. converter shown in Figure 10. As a result, each machine is directly connected to the grid through this a.c. converter. The partially centralized approach split the distorted voltage-d.c. conversion from the d.c.-a.c. conversion (see Figure 11). It leaves the rectifiers on each single generator and connect all the outputs of the rectifiers to a common d.c. bus. If the d.c. link voltage falls under a critical value, the generator must be disconnected from the grid because it does not input any power. As a result, the buffer capacitance plays a role and should be used in an optimal way. The inverter is centralized and use as d.c. link the bus where all the generators are connected. In both cases between the transformer and the grid there is a filter that is not depicted in this figure.

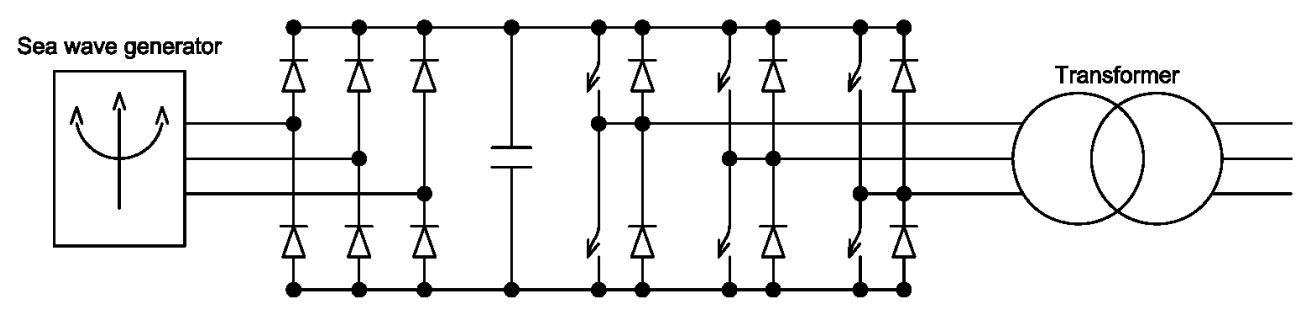

Figure 10. Decentralized approach to the interconnection of a seawave generator to the grid.

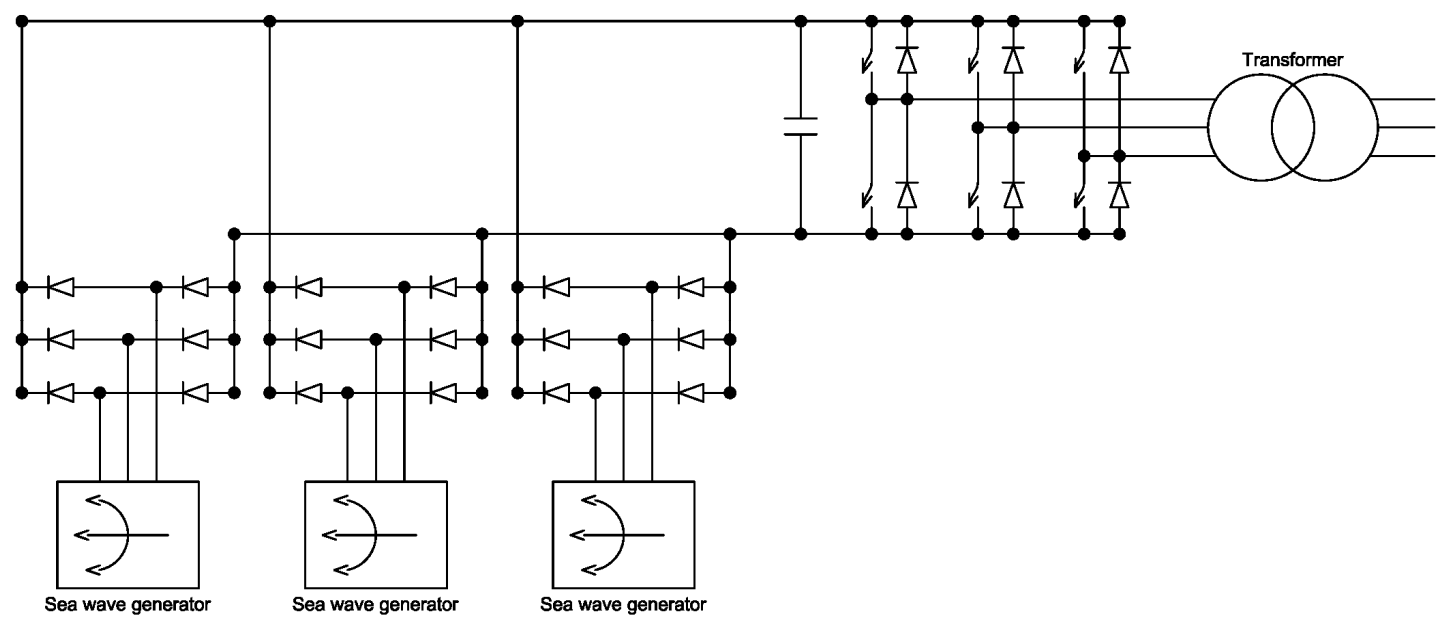

Figure 11. Partially centralized approach to the interconnection of several seawave generators to the grid.

\section{Scenarios}

This work proposes four different Renewable Energies Sources (RES) in order to satisfy most of the island's electricity request: solar source, wind source, wave source and geothermal one. In this way, the use of a RE mix is able to reduce significantly the energetic dependence of Pantelleria and the emissions of GHG due to the combustion of fossil fuels of the S.MED.E. thermal power plant, which will have only a minor role.

\subsection{Solar Source}

Solar energy is certainly one of the most promising sources, thanks to the possibility to exploit it everywhere: in an agricultural, an industrial or an urban area, etc. This work is exclusively focused 
on the use of photovoltaic (PV) technology, which is able to convert solar radiation into an electrical output, although the use of solar thermal panels is still highly recommended. PV technology now has very high standards, thanks to its characteristic of modularity, great reliability and low maintenance. In this work the installation of PV panels on building roofs is assumed, in order to avoid the use of the small island's land [42]. Furthermore, in order to preserve buildings of relevance from a historical point of view, we excluded the installation on buildings like "Dammusi" and "Giardini Panteschi", so the installation of photovoltaic panels is concentrated around the hall city. Figure 12 shows the available areas for the installation of photovoltaic panels in a quarter surrounding the city hall.

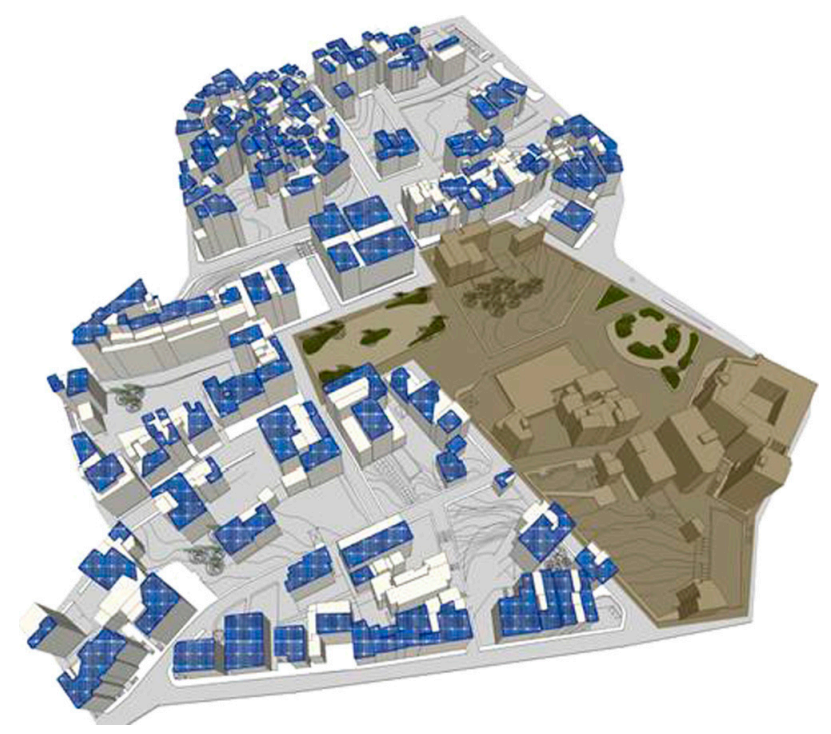

Figure 12. Rendering view of the available areas for the installation of solar photovoltaic panels in the quarter surrounding the city hall.

Nowadays, the innovative technologies contribute to the very low visual impact of the installations while, at the same time, increasing the efficiency and the panels' cost reduction are increasing the use of this important source. Moreover, Pantelleria is characterized by a very high annual solar radiation, about 1.69 MWh $/\left(\mathrm{m}^{2}\right.$.year) [11]. The monthly solar radiation is higher in summer season and lower in winter, so it has the same trend of the electrical energy demand (see Table 1).

Table 1. Solar radiation data in Pantelleria.

\begin{tabular}{cc}
\hline Parameter & Value \\
\hline Average annual solar radiation & $1.69 \mathrm{MWh} /\left(\mathrm{m}^{2} \cdot\right.$ year $)$ \\
Minimum daily solar radiation (January) & $1.90 \mathrm{kWh} /\left(\mathrm{m}^{2} \cdot\right.$ day $)$ \\
Maximum daily solar radiation (July) & $7.20 \mathrm{kWh} /\left(\mathrm{m}^{2} \cdot\right.$ day) \\
\hline
\end{tabular}

In order to maximize the electrical energy output, the photovoltaic panels will be installed on the roofs of residential builds, with a tilt angle of about $30^{\circ}$. In this way, the visual impact is also minimized. Of course, the installation of solar thermal panels for the hot water production could play an important role in the process of reduction of fossil energy consumption. However, in this paper we consider only the technologies able to directly produce electrical energy, in order to replace the equivalent production of energy from fossil fuels.

According to this assumption, we consider the installation of $1.5 \mathrm{MW}$ in the building's roofs, able to produce $2440 \mathrm{MWh}$ /year [12], which represents an amount of electrical energy that will not be produced by S.MED.E. power plant. Using the $\mathrm{CO}_{2}$ emission factor reported in [12], this electrical energy production will be able to avoid $1950 \mathrm{t} /$ year of greenhouse gases emissions. 


\subsection{Wind Source}

Wind energy represents a very important RE for the island of Pantelleria, which is characterized by a favorable wind weather. Furthermore, electrical energy production from wind source is very cheap, comparable to other RE. Like the wave energy potential, the wind one has a prevailing north-west direction [12]. Obviously, the wind source seasonal trend is similar to that of the wave source, with the highest values in winter and lowest values in summer. Moreover, the energy potential increases significantly with the distance from the land.

In this text we suppose the use of small horizontal axis wind turbines, in order to limit the visual impact in the territory. The generator could be installed in "Contrada Arenella", an area located in the northern part of the island (see Figure 13). In this way the electrical energy generation is near to center of consumption.
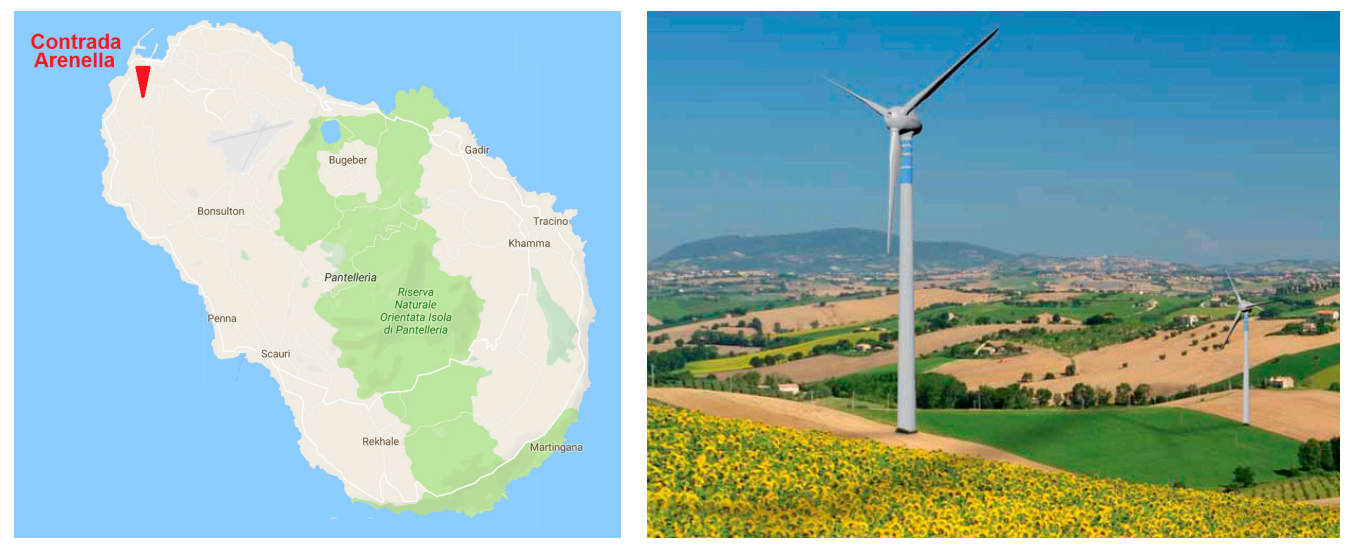

Figure 13. Location on "Contrada Arenella" and a rendering view of a wind farm.

The selection process of wind turbines considered two opposite aspects: energy production and environmental impact. The first aspect suggests the choice of big wind turbines, in order to maximize the energy production from the single machine, thanks the greater height of the device and the greater area, swept by the rotor. On the other side, a bigger turbine presents a greater visual impact, due its greater dimensions. According these aspects, we considered the installation of a wind farm, composed by 50 wind turbines, each one having a rated power of $50 \mathrm{~kW}$, so the overall installed power is $2.5 \mathrm{MW}$.

Table 2 summarizes the main data about the wind turbine used in the simulation [43]. We estimated an annual electrical energy production of about $6250 \mathrm{MWh} /$ year [12]. This electrical energy production will be able to avoid $5000 \mathrm{t}$ /year of greenhouse gases emissions.

Table 2. Wind turbine data.

\begin{tabular}{cc}
\hline Parameter & Value \\
\hline Rated power & $50 \mathrm{~kW}$ \\
Cut-in speed & $3 \mathrm{~m} / \mathrm{s}$ \\
Cut-off speed & $25 \mathrm{~m} / \mathrm{s}$ \\
Rotor diameter & $18 \mathrm{~m}$ \\
Rotor surface & $254 \mathrm{~m}^{2}$ \\
Hub height & $25 \mathrm{~m}$ \\
Rotational speed & $25-70 \mathrm{rpm}$ \\
\hline
\end{tabular}

\subsection{Geothermal Source}

Pantelleria is an island of volcanic origin. In fact, at the present time there are several examples of volcanic activities, such as fumaroles and natural hot waters. This important characteristic can be properly exploited to produce electrical energy in the island without the combustion of fossil 
fuels. The electrical energy production from geothermal sources is quite cheap too, because it presents a consolidated technology. Indeed, a geothermal power plant is very similar to a traditional thermoelectric one based on the combustion of fossil fuel, such as coal, petroleum derivatives or natural gas.

The most important advantage of a geothermal power plant is represented by the free natural heat from the Earth, caused by a particularly favorable geothermal gradient. In this way, the hot water obtained from geothermal wells is suitably treated and canalized in the pipes, in order to undergo an expansion within the turbine, with a classical thermodynamic cycle. On the other hand, the most important disadvantages are represented by the visual impact of the building (like any other power plant) and the emission of nasty smells, due to the natural presence of hydrogen sulphide. The first issue can be avoided thanks to the use of stone drywall (which are typical of the architecture of the island), while the second one can be mitigated through the use of appropriate abatement equipment. Many geological studies have been realized in the last sixty years by International Institute for Geothermal Research (IIRG) and the National Research Council (CNR). In particular, four exploration pits have been dug at different locations: Gadir, Kazen, Nikà e Bagno dell'Acqua, as shown in Figure 14. In 1992, thanks the "VALOREN" project, four other exploration pits have been realized with a depth ranging from 180 to $400 \mathrm{~m}$; these sites are indicated in the maps as PT1, PT2, PT3 and PT4. Finally, in 1993 other two exploitation pits have been dug (PPT1 and PPT2) in order to verify the real temperatures at greater depth (about $1100 \mathrm{~m}$ ), obtain data about the geological structure in the subsoil and evaluate the geothermal resource.

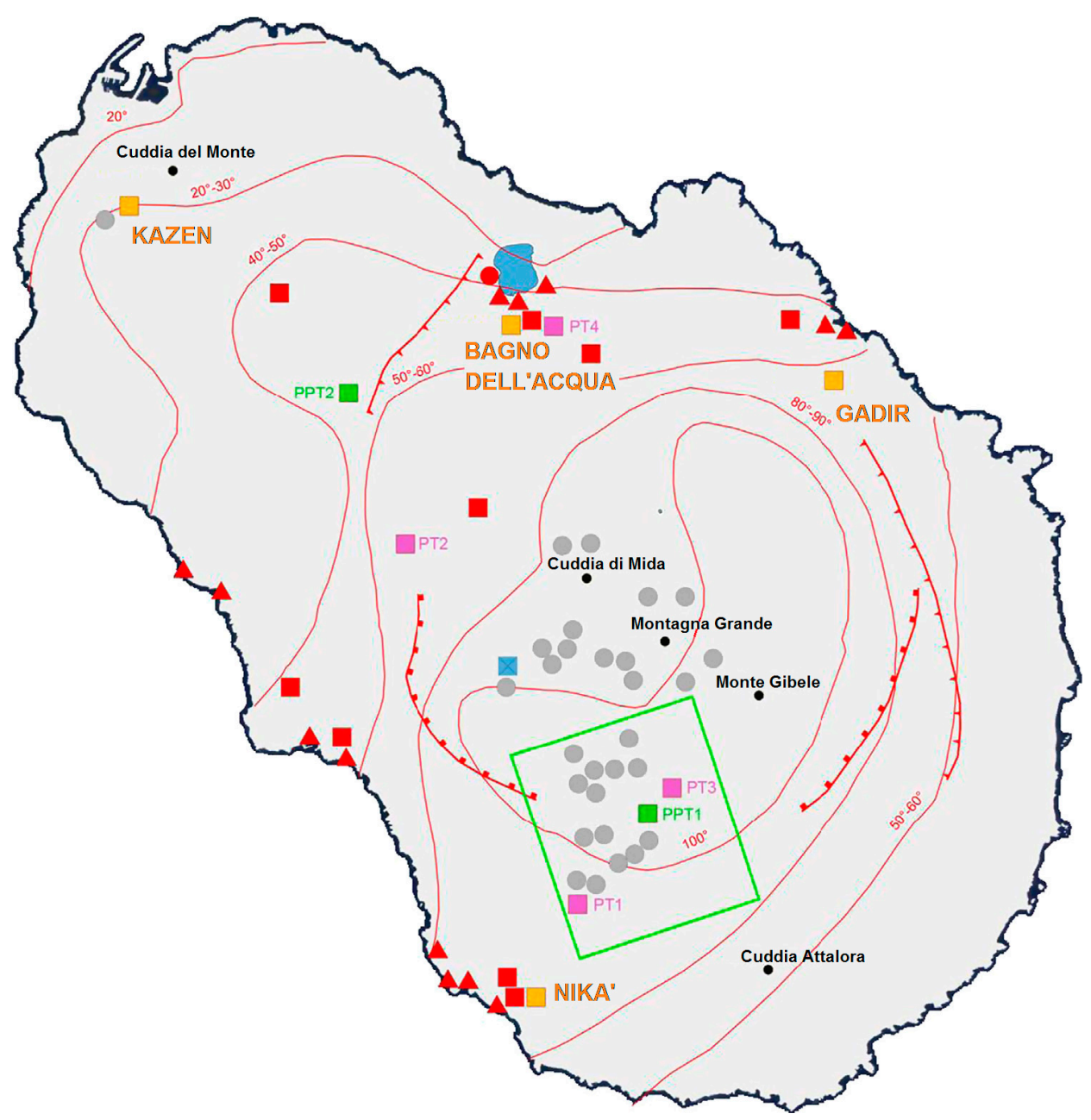

Figure 14. Exploration pits for geothermal source. 
Table 3 reports the main data about the geothermal resource in PPT1 [44,45]. Using the assumptions reported in Table 4, we evaluate the installation of a condensing steam power plant by geothermal source in the southern part of the island (PPT1 in the Figure 14), having a nominal power of $500 \mathrm{~kW}$. This plant will be able to produce about $4000 \mathrm{MWh} /$ year. This is an important production, due to the high working rate of the power plant, about $8000 \mathrm{~h} /$ year (more than the other renewable sources) [11]. Finally, it will be able to avoid about $3200 \mathrm{t} /$ year of greenhouse gases emissions.

Table 3. Data about the geothermal resource.

\begin{tabular}{cc}
\hline Parameter & Value \\
\hline Available flow & $4 \mathrm{t} / \mathrm{h}$ \\
Temperature & $250{ }^{\circ} \mathrm{C}$ \\
Pressure & $13.5 \mathrm{bar}$ \\
Enthalpy & $2929.9 \mathrm{~kJ} / \mathrm{kg}$ \\
\hline
\end{tabular}

Table 4. Steam cycle properties.

\begin{tabular}{cc}
\hline Parameter & Value \\
\hline Steam flow & $2.7 \mathrm{t} / \mathrm{h}$ \\
Condensing pressure & $0.05 \mathrm{bar}$ \\
Isentropic Efficiency & 0.8 \\
Organic Efficiency & 0.96 \\
Power output & $500 \mathrm{~kW}$ \\
Annual working hours & $8000 \mathrm{~h} / \mathrm{y}$ \\
Annual electrical production & $4 \mathrm{GWh}$ \\
\hline
\end{tabular}

\subsection{Wave Source}

Wave energy production in the Mediterranean Sea is especially appealing for countries having relatively long coastlines. Obviously, electrical energy production from seawaves with innovative conversion devices will be really feasible only with extensive studies about wave energy potential in the interested areas, a detailed knowledge about energy occurrence, about its temporal and spatial variability and about its energy distribution among different sea states. Particularly, wave energy represents a very important RE for the island of Pantelleria and, in general, for all the Mediterranean islands.

The conversion of wave energy into electrical output, through the use of the innovative Point Absorber here proposed, will be able to satisfy a significant part of the annual electrical energy request, reducing the energy dependence of the island on exogenous fossil fuels, imported from other countries characterized by a constant geopolitical instability. Moreover, this production occurs without any emission of GHG and without the use of land on the mainland. Another remarkable advantage is represented by the creation of a supply chain in local areas that does not exist nowadays. Obviously the installation of the wave farms, in the northern part of the island will not be in conflict with the main trade and military routes.

Thanks to the small dimensions of the DEIM WEC, every wave farm will be composed of three arrays of 10 devices each, increasing their nominal power. The energy production is obtained with an overall efficiency of $50 \%$, multiplying the diameter of the cut-off buoy by the local seawave power. Finally, the installation of two wave farms, for a gross power of $9.6 \mathrm{MW}$, will produce about $18,400 \mathrm{MWh}$ /year, with a working rate of $1910 \mathrm{~h} /$ year. This electrical energy production will be able to avoid 14,720 $\mathrm{t} /$ year of greenhouse gases emissions. The wave source thus represents an important item, satisfying about $42 \%$ of the annual electrical demand. 


\section{Conclusions}

Wave energy conversion has recently dominated the debate about renewable energies, due to its high potential, much higher than that of other green energy sources. Although its distribution throughout the planet is not homogeneous, even mild seas like those found in the Italian offshore areas can be suitable for wave energy conversion. However, the mild wave climate of these locations requires a resizing of the conventional devices, which are usually designed to be deployed in the Atlantic, where the wave potential is much higher. Such modifications tend to reduce the size of the single device and to deploy it in an array of several units, to take advantage of the less energetic wave climate without losing energy extraction capacity. The aim of this work was to evaluate the sea-based device feasibility for wave energy exploitation under Mediterranean Sea conditions installed near Pantelleria Island. A numerical model of the coupled buoy-generator system was developed to simulate the behavior of the wave energy converter in regular waves of different wave heights and periods. This simplified model can be used to estimate the electrical power output of the wave energy converter, varying the parameters of the device. In this way, the wave energy converter can be optimized to a specific wave climate. In order to realize a wave farm, two different electrical interconnection solutions are presented. In the first hypothesis, each wave energy converter (WEC) is connected directly to the electrical grid, through an a.c.-a.c. converter. In the second hypothesis, the electrical output of several WECs is firstly converted into d.c, then a singular d.c.-a.c converter transfers the energy into the electrical grid. In the future, other investigations will be carried out in order to assess which of these two solutions has a lower cost and greater reliability.

The study case, applied to the island of Pantelleria, shows that the greater part of the electrical energy demand can be satisfied by renewable energy sources (RES), in particular sea waves, thanks the huge energy potential. Table 5 and Figure 15 summarize the energy scenario evaluated in the previous section.

Table 5. Electrical production and avoided $\mathrm{CO}_{2}$ emissions by sources.

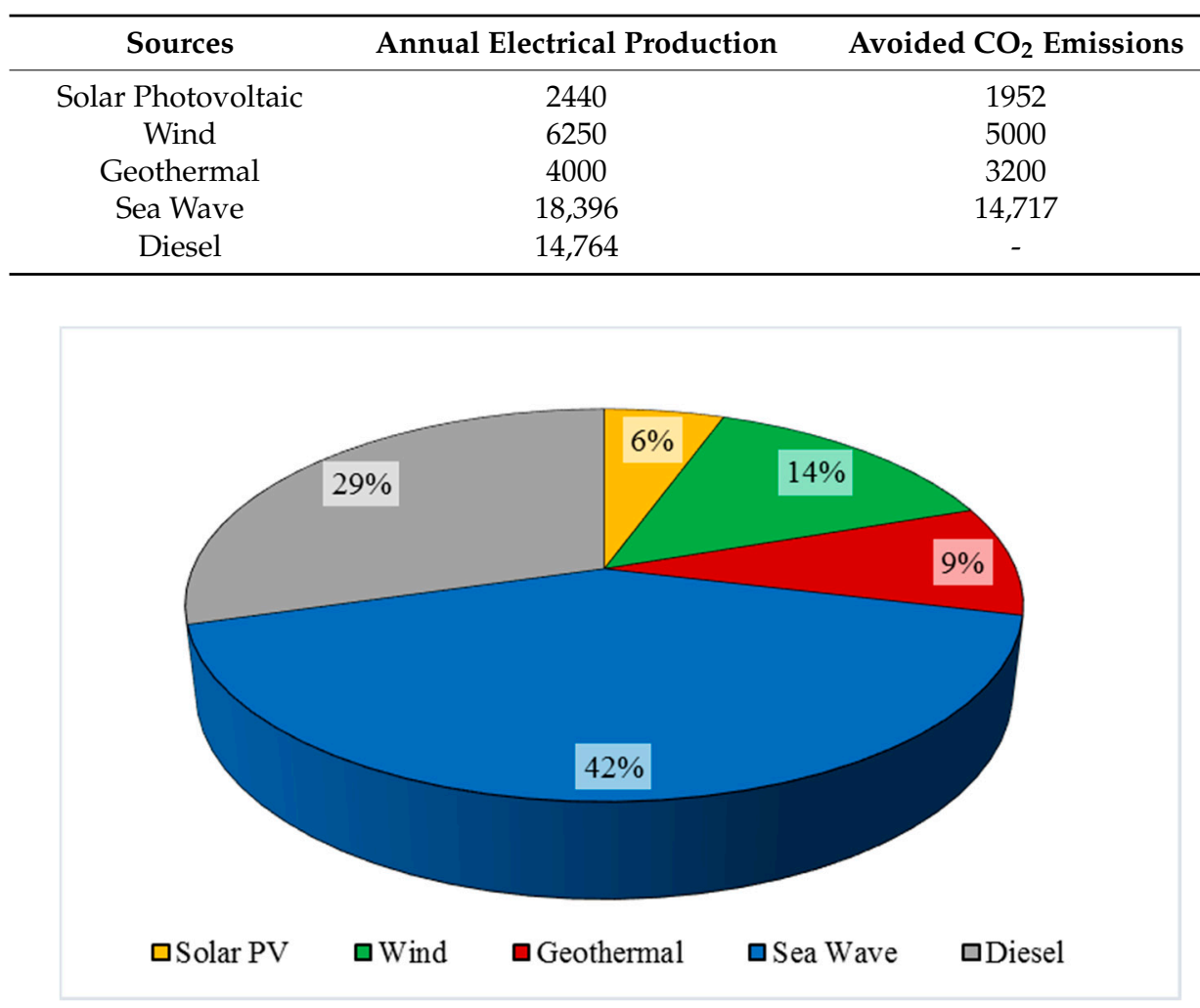

Figure 15. Energetic scenario by sources. 
In this scenario, the total energy production from RES is estimated to be about $31,086 \mathrm{MWh}$ /year, which represents $71 \%$ of the electrical energy production in 2013. In this way, there will be a reduction of burned fossil fuels, a greater energy independence of the island and a significant reduction of GHG emissions. Globally, this production will be able to avoid about $24,870 \mathrm{t} /$ year of $\mathrm{CO}_{2}$, which represents a key goal for the near future.

Conflicts of Interest: The authors declare no conflict of interest.

\section{Abbreviations}

\begin{tabular}{|c|c|}
\hline$H_{S}$ & Significant height of sea waves \\
\hline$T_{p}$ & Peak period of sea waves \\
\hline$D_{p}$ & Main direction of sea waves \\
\hline$m$ & Total mass of power take off system \\
\hline$m_{a}$ & Mass of the fluid, displaced by the buoy \\
\hline$y(t)$ & Vertical position of the floating buoy, measured from the equilibrium condition \\
\hline$\dot{y}(t)$ & Vertical speed of the floating buoy \\
\hline$\dot{\eta}(t)$ & Vertical velocity of the free water surface \\
\hline$\ddot{y}(t)$ & Vertical acceleration of the floating buoy \\
\hline$F_{H}(t)$ & Sum of the hydrodynamic forces applied to the power take off system \\
\hline$F_{R}(t)$ & Sum of the resistance forces applied to the power take off system \\
\hline$F_{M}(t)$ & Electromagnetic braking force \\
\hline$F_{K}(t)$ & Elastic force of the spring system \\
\hline$R_{D}$ & Radiation damping coefficient \\
\hline$C_{D}$ & Viscous damping coefficient \\
\hline$\rho$ & Sea water density \\
\hline$S$ & Water plane area of the body at rest \\
\hline$g$ & Gravitational acceleration constant \\
\hline$F_{e}$ & Amplitude of the excitation force \\
\hline$H$ & Wave height \\
\hline$\omega$ & Wave frequency \\
\hline$\alpha$ & Wave angular phase \\
\hline K & Elastic stiffness constant of the spring \\
\hline$e(t)$ & Voltage generated in the stator \\
\hline$B_{t}$ & Magnetic field evaluated in stator tooth \\
\hline$w_{t}$ & Width of a stator tooth \\
\hline$d$ & Width of the stator stack \\
\hline$p$ & Total number of poles \\
\hline$s$ & Number of slots per pole and phase \\
\hline$c$ & Number of coils in a slot \\
\hline$w_{p}$ & Pole width \\
\hline$\delta$ & Load angular phase \\
\hline$V(t)$ & Output voltage in the electrical generator \\
\hline$I(t)$ & Output current in the electrical generator \\
\hline$\frac{d I(t)}{d t}$ & Time derivative of the current \\
\hline$R_{i}$ & Internal resistance of the windings \\
\hline$R_{\text {load }}$ & Load resistance \\
\hline$L$ & Circuit inductance \\
\hline$P(t)$ & Output power of the electrical generator \\
\hline
\end{tabular}

\section{References}

1. Di Dio, V.; Franzitta, V.; Milone, D.; Pitruzzella, S.; Trapanese, M.; Viola, A. Design of Bilateral Switched Reluctance Linear Generator to Convert Wave Energy: Case Study in Sicily. Adv. Mater. Res. 2013, 860, 1694-1698. [CrossRef] 
2. Franzitta, V.; Milone, A.; Milone, D.; Pitruzzella, S.; Trapanese, M.; Viola, A. Experimental Evidence on the Thermal Performance of Opaque Surfaces in Mediterranean Climate. Adv. Mater. Res. 2014, 860, 1227-1231. [CrossRef]

3. Franzitta, V.; Rizzo, G. Renewable energy sources: A Mediterranean perspective. In Proceedings of the 2010 2nd International Conference on Chemical, Biological and Environmental Engineering, Cairo, Egypt, 2-4 November 2010; pp. 48-51.

4. Franzitta, V.; Milone, D.; Trapanese, M.; Viola, A.; di Dio, V.; Pitruzzella, S. Energy and Economic Comparison of Different Conditioning System among Traditional and Eco-Sustainable Building. Appl. Mech. Mater. 2013, 394, 289-295. [CrossRef]

5. Cannistraro, G.; Cannistraro, M.; Cannistraro, A.; Galvagno, A.; Trovato, G. Reducing the Demand of Energy Cooling in the CED, 'Centers of Processing Data', with Use of Free-Cooling Systems. Int. J. Heat Technol. 2016, 34, 498-502. [CrossRef]

6. Franzitta, V.; Curto, D.; Rao, D. Energetic Sustainability Using Renewable Energies in the Mediterranean Sea. Sustainability 2016, 8, 1164. [CrossRef]

7. Gestore Servizi Energetici. Rapporto Statistico-Energia da Fonti Rinnovabili-Anno 2013; Gestore Servizi Energetici (GSE): Rome, Italy, 2015.

8. Cagninei, A.; Raffero, M.; Bracco, G.; Giorcelli, E.; Mattiazzo, G.; Poggi, D. Productivity analysis of the full scale inertial sea wave energy converter prototype: A test case in Pantelleria Island. J. Renew. Sustain. Energy 2015, 7, 61703. [CrossRef]

9. Bueno, C.; Carta, J.A. Wind powered pumped hydro storage systems, a means of increasing the penetration of renewable energy in the Canary Islands. Renew. Sustain. Energy Rev. 2006, 10, 312-340. [CrossRef]

10. Franzitta, V.; Curto, D.; Rao, D.; Milone, D. Near zero energy island with sea wave energy: The case study of Pantelleria in Mediterranean Sea. In Proceedings of the OCEANS 2016, Shanghai, China, 10-13 April 2016; pp. 1-5.

11. Sanseverino, E.R.; Sanseverino, R.R.; Favuzza, S.; Vaccaro, V. Near zero energy islands in the Mediterranean: Supporting policies and local obstacles. Energy Policy 2014, 66, 592-602. [CrossRef]

12. Piano D'azione per L'energia Sostenibile del Comune di Pantelleria. Available online: http://www. smartisland.eu/images/documenti_report/Pantelleria_Paes.pdf (accessed on 9 December 2016).

13. Cannistraro, G.; Cannistraro, M.; Piccolo, A.; Restivo, R. Potentials and Limits of Oxidative Photocatalysisand Possible Applications in the Field of Cultural Heritage. Adv. Mater. Res. 2013, 787, 111-117. [CrossRef]

14. Cannistraro, G.; Cannistraro, M. Hypothermia Risk, Monitoring and Environment Control in Operating Rooms. Int. J. Heat Technol. 2016, 34, 165-171. [CrossRef]

15. Tuttitalia.it. Popolazione Pantelleria 2001-2015. Statistiche Demografice. 2016. Available online: http:/ / www.tuttitalia.it/sicilia/31-pantelleria/statistiche/popolazione-andamento-demografico/ (accessed on 13 November 2016).

16. Cosentino, V.; Favuzza, S.; Graditi, G.; Ippolito, M.G.; Massaro, F.; Sanseverino, E.R.; Zizzo, G. Smart renewable generation for an islanded system. Technical and economic issues of future scenarios. Energy 2012, 39, 196-204. [CrossRef]

17. Viola, A.; Franzitta, V.; Trapanese, M.; Curto, D. Nexus Water \& Energy: A Case Study of Wave Energy Converters (WECs) to Desalination Applications in Sicily. Int. J. Heat Technol. 2016, 34, S379-S386.

18. Peviani, M.; Carli, F.; Bonamano, S. Mappa del Potenziale Energetico dal Moto Ondoso Nelle Coste Italiane; Ricerca Sistema Energetico (RSE): Milan, Italy, 2011.

19. Booij, N.; Ris, R.C.; Holthuijsen, L.H. A third-generation wave model for coastal regions: 1. Model description and validation. J. Geophys. Res. Ocean. 1999, 104, 7649-7666. [CrossRef]

20. Liberti, L.; Sann, G.; Carillo, A. Wave energy potential in the Mediterranean, the case of Pantelleria. In Proceedings of the OWEMES (Offshore Wind and Other Marine Renewable Energies) 2012, Rome, Italy, 5-7 September 2012.

21. Franzitta, V.; Trapanese, M.; Giaconia, C.; Ferrara, P.; Viola, A. Design and experimental test of a low costweather buoy. In Proceedings of the 2013 MTS (Marine Technology Society)/IEEE (Institute of Electrical and Electronics Engineers) OCEANS, Bergen, Norway, 10-13 June 2013; pp. 1-5.

22. Mattiazzo, G.; Giorcelli, E.; Poggi, D.; Sannino, G.; Carillo, A. Progettazione di un Sistema di Produzione di Energia da Moto Ondoso in Scala Reale; Agenzia nazionale per le nuove tecnologie, l'energia e lo sviluppo economico sostenibile (ENEA): Rome, Italy, 2013. 
23. Lockett, F.P. Mathematical modelling of wave energy systems. Renew. Energy 1996, 9, 1213-1217. [CrossRef]

24. Franzitta, V.; Viola, A.; Trapanese, M. Design of a transverse flux machine for power generation from seawaves. J. Appl. Phys. 2014, 115, 17E712. [CrossRef]

25. Bonanno, A.; Franzitta, V.; Muzio, F.P.; Trapanese, M. A multiphysics approach to the design of a seawave energy conversion system. In Proceedings of the 2008 IEEE International Conference on Sustainable Energy Technologies, Singapore, 24-27 November 2008; pp. 665-668.

26. McCabe, A.P.; Aggidis, G.A. Optimum mean power output of a point-absorber wave energy converter in irregular waves. Proc. Inst. Mech. Eng. Part A J. Power Energy 2009, 223, 773-781. [CrossRef]

27. Munson, B.R.; Young, D.F.; Okiishi, T.H.; Huebsch, W.W. Fundamentals of Fluid Mechanics, 6th ed.; Wiley: Somerset, NJ, USA, 2009.

28. McCormick, M.E. Ocean Engineering Mechanics; Cambridge University Press: Cambridge, UK, 2009.

29. Thorburn, K.; Leijon, M. Farm size comparison with analytical model of linear generator wave energy converters. Ocean Eng. 2007, 34, 908-916. [CrossRef]

30. Trapanese, M.; Franzitta, V.; Viola, A. A dynamic model for hysteresis in magnetostrictive devices. J. Appl. Phys. 2014, 115, 1-4. [CrossRef]

31. Miceli, R.; Trapanese, M. Evaluation of the power quality from a seawave power farm for different interconnection schemes. In Proceedings of the OCEANS 2007, Aberdeen, UK, 18-21 June 2007; pp. 1-4.

32. Bozzi, S.; Miquel, A.; Antonini, A.; Passoni, G.; Archetti, R. Modeling of a Point Absorber for Energy Conversion in Italian Seas. Energies 2013, 6, 3033-3051. [CrossRef]

33. ANSYS Inc. AQWA User Manual-Release 14.5. Available online: https://cyberships.files.wordpress.com/ 2014/01/wb_aqwa.pdf (accessed on 9 December 2016).

34. Falnes, J. Ocean Waves and Oscillating Systems: Linear Interactions Including Wave-Energy Extraction; Cambridge University Press: Cambridge, UK, 2002.

35. Milone, D.; Pitruzzella, S.; Franzitta, V.; Viola, A.; Trapanese, M. Energy savings through integration of the illumination natural and artificial, using a system of automatic dimming: Case study. Appl. Mech. Mater. 2013, 372, 253-258. [CrossRef]

36. Franzitta, V.; di Dio, V.; Viola, A.; Giaconia, C.; Ferrara, P.; Trapanese, M. Experimental results of a low cost weather buoy. In Proceedings of the 2013 OCEANS, San Diego, CA, USA, 23-27 September 2013.

37. Silva, D.; Rusu, E.; Soares, C. Evaluation of Various Technologies for Wave Energy Conversion in the Portuguese Nearshore. Energies 2013, 6, 1344-1364. [CrossRef]

38. Rusu, E. Evaluation of the Wave Energy Conversion Efficiency in Various Coastal Environments. Energies 2014, 7, 4002-4018. [CrossRef]

39. Vantorre, M.; Banasiak, R.; Verhoeven, R. Modelling of hydraulic performance and wave energy extraction by a point absorber in heave. Appl. Ocean Res. 2004, 26, 61-72. [CrossRef]

40. Polinder, H.; Damen, M.E.C.; Gardner, F. Linear PM Generator System for Wave Energy Conversion in the AWS. IEEE Trans. Energy Convers. 2004, 19, 583-589. [CrossRef]

41. Boscaino, V.; Cipriani, G.; Curto, D.; di Dio, V.; Franzitta, V.; Trapanese, M.; Viola, A. A small scale prototype of a wave energy conversion system for hydrogen production. In Proceedings of the IECON 2015 41st Annual Conference of the IEEE Industrial Electronics Society, Yokohama, Japan, 9-12 November 2015.

42. Franzitta, V.; Milone, A.; Milone, D.; Pitruzzella, S.; Trapanese, M.; Viola, A. A Case Study to Evaluate the Indoor Global Quality. Adv. Mater. Res. 2013, 864, 1054-1058. [CrossRef]

43. Aerogeneratore ItalTech $50 \mathrm{~kW}$-DataSheet. 2016. Available online: http://www.italtechwind.it/it/utility/ pdf/aerogeneratore_italtechwind_60kw.pdf (accessed on 20 January 2017).

44. Mattia, M.; Bonaccorso, A.; Guglielmino, F. Ground deformations in the Island of Pantelleria (Italy): Insights into the dynamic of the current intereruptive period. J. Geophys. Res. 2007, 112, B11406. [CrossRef]

45. Gianelli, G.; Grassi, S. Water-rock interaction in the active geothermal system of Pantelleria, Italy. Chem. Geol. 2001, 181, 113-130. [CrossRef]

(c) 2017 by the authors. Licensee MDPI, Basel, Switzerland. This article is an open access article distributed under the terms and conditions of the Creative Commons Attribution (CC BY) license (http:/ / creativecommons.org/licenses/by/4.0/). 